\title{
Radioiodine therapy in skeletal metastases from well-differentiated thyroid cancer: a Johannesburg experience
}

\author{
Nalini Sindy Perumal, $M B B C h$, FCNP \\ Mboyo-Di-Tamba Heben Willy Vangu, $M D$, \\ MMed, MSc \\ Division of Nuclear Medicine, Charlotte Maxeke Johannesburg Academic \\ Hospital and University of the Witwatersrand, Johannesburg
}

\begin{abstract}
Aim.The purpose of this study was to examine the outcome of patients with skeletal metastases from well-differentiated thyroid carcinoma and analyse the effect of variables that influence the prognosis of this disease.

Method. We retrospectively reviewed 352 patients treated and followedup at the Charlotte Maxeke Johannesburg Academic Hospital's thyroid cancer clinic from 1982 - 1999.

Findings. Skeletal metastases were diagnosed in 24 (6.8\%), 17 at presentation to the thyroid clinic, and 7 at follow-up. Patients' ages ranged from 30 - 77 years (mean 53.9 years) and the female:male ratio was 3.8:1. Based on the original pathology reports from resected tumours, 9 were papillary and 15 were follicular cancers. Twenty-three of the 24 patients underwent thyroid surgery as the initial management - total thyroidectomy in 18 , subtotal thyroidectomy in 3 , and lobectomy plus neck dissection in one. The diagnosis of thyroid cancer was based on lobectomy in a single subject. Radioactive iodine (RAI) was used as part of the original treatment; external radiation therapy (XRT) was mainly used to alleviate severe symptoms. Twenty-one patients $(87.5 \%)$ were treated with RAI; 11 (45.8\%) received radiotherapy. Seven patients died - 4 from neurological disease directly associated with bone metastases. Of the 17 surviving patients, 2 appeared to be disease-free, 8 were asymptomatic despite overt bony disease, and 7 had persistent symptoms which much improved in 5. Bone metastases were uncommon, and follicular cancer predominated in this survey.

Conclusion. RAI therapy improves quality of life in most patients. There is a place for XRT.
\end{abstract}

\section{Introduction}

Thyroid cancer is a rare disease, and the controversy surrounding the treatment of well-differentiated types continues. ${ }^{1}$ One can readily note this position in the optimal extent of primary thyroid resection in most patients with papillary thyroid carcinoma, who are at lower or minimal risk of mortality. It is necessary to follow a large number of patients for a long time to assess the effectiveness of a particular therapeutic modality. The presence of distant metastases from differentiated thyroid carcinoma decreases the 10-year survival of patients by $50 \%$ (from $80-90 \%$ down to $40 \%$ ). The methods used more than 15 years ago for diagnosis and treatment differ from present-day management. ${ }^{2}$ More recent studies show that survival drops to $13-21 \%$ when bone metastases are present. $^{3-5}$ Bone metastases represent a frequent complication, especially of follicular thyroid cancer, and severely reduce quality of life, causing pain, fractures and spinal cord compression. The objective of this study was to look retrospectively at the outcomes of patients with skeletal metastases from well-differentiated thyroid carcinoma and to consider the impact of several variables influencing the prognosis of this illness.

\section{Materials and methods}

Our study was based on the analysis of treatment of 352 patients treated and followed-up from 1982 - 1999 at the Johannesburg Hospital thyroid cancer clinic, University of the Witwatersrand.

Patients' information was available from records kept by the thyroid cancer clinic, which is part of the Division of Nuclear Medicine. Twenty-

\begin{tabular}{|c|c|c|c|c|c|}
\hline \multicolumn{6}{|c|}{$\begin{array}{l}\text { Table I. Clinical characteristics of the } 24 \text { patients with } \\
\text { skeletal metastases }\end{array}$} \\
\hline $\begin{array}{l}\text { Patient } \\
\text { no. }\end{array}$ & Sex & $\begin{array}{l}\text { Age } \\
\text { (years) }\end{array}$ & $\begin{array}{l}\text { Histology } \\
\text { type }\end{array}$ & $\begin{array}{l}\text { Cap- } \\
\text { sule in- } \\
\text { volve- } \\
\text { ment }\end{array}$ & $\begin{array}{l}\text { Follow- } \\
\text { up } \\
\text { (months) }\end{array}$ \\
\hline 1 & F & 59 & Fo & Yes & 27 \\
\hline 2 & $\mathrm{~F}$ & 30 & $\mathrm{~Pa}$ & No & 132 \\
\hline 3 & $\mathrm{M}$ & 48 & $\mathrm{~Pa}$ & Yes & 41 \\
\hline 4 & $\mathrm{~F}$ & 69 & Fo & Yes & 39 \\
\hline 5 & F & 65 & Fo & Yes & 84 \\
\hline 6 & $\mathrm{~F}$ & 32 & $\mathrm{~Pa}$ & No & 74 \\
\hline 7 & $\mathrm{~F}$ & 52 & Fo & Yes & 75 \\
\hline 8 & M & 66 & Fo & Yes & 66 \\
\hline 9 & $\mathrm{~F}$ & 37 & $\mathrm{~Pa}$ & No & 148 \\
\hline 10 & $\mathrm{~F}$ & 77 & Fo & Yes & 103 \\
\hline 11 & F & 51 & Fo & Yes & 2 \\
\hline 12 & F & 57 & Fo & Yes & 4 \\
\hline 13 & $\mathrm{~F}$ & 47 & $\mathrm{~Pa}$ & Yes & 170 \\
\hline 14 & $\mathrm{~F}$ & 58 & $\mathrm{~Pa}$ & Yes & 51 \\
\hline 15 & $\mathrm{M}$ & 55 & Fo & Yes & 4 \\
\hline 16 & $\mathrm{~F}$ & 70 & Fo & Yes & 15 \\
\hline 17 & $\mathrm{M}$ & 54 & Fo & Yes & 18 \\
\hline 18 & F & 69 & $\mathrm{~Pa}$ & Yes & 30 \\
\hline 19 & F & 37 & Fo & Yes & 2 \\
\hline 20 & $\mathrm{~F}$ & 65 & Fo & Yes & 46 \\
\hline 21 & $\mathrm{M}$ & 59 & $\mathrm{~Pa}$ & Yes & 43 \\
\hline 22 & $\mathrm{~F}$ & 66 & Fo & Yes & 3 \\
\hline 23 & $\mathrm{~F}$ & 31 & $\mathrm{~Pa}$ & Yes & 25 \\
\hline 24 & $\mathrm{~F}$ & 40 & Fo & Yes & 60 \\
\hline
\end{tabular}


four patients (6.8\%) had skeletal metastases that were diagnosed on iodine scans and one or more other modalities. The median follow-up of this group of patients with bony metastases was 39 months (range 2 - 170 months).

The patients' ages ranged from 30 - 77 years (mean 53.9). Patients were categorised into papillary and follicular types, depending on histological reports. Only the original reports of pathology tests at the time of initial referral were used, and the papillary cancer included both purely papillary and mixed papillary-follicular tumours. Follicular cancer therefore had no papillary elements.

Radioiodine was used as part of the original treatment, whereas external radiation therapy was used to control symptoms, principally at presentation.

\section{Results}

Clinical characteristics of this group of patients are summarised in Table I.

Eighteen of these patients were female. Follicular carcinoma was diagnosed in 15 patients, and the balance had papillary carcinoma of the thyroid. All but one patient underwent surgery for the primary disease. Eighteen had total thyroidectomy, 2 had sub-total thyroidectomy, 1 had a total lobectomy plus a contralateral sub-total lobectomy, and 1 had a total lobectomy plus neck dissection.
Therapeutic modalities used in our group of patients are shown in Table II. Twenty-one patients were treated with radioactive iodine (RAI); of these, 13 were given RAI to ablate the residual thyroid gland tissue following surgery, and 8 patients received it for ablation of the residual thyroid gland tissue and treatment of metastatic cancer disease at the same time. In the former group, 9 patients showed abnormal uptake compatible with metastatic disease on the ablative scans. The amount of RAI received by these patients ranged from $30-300 \mathrm{mCi}$ depending on thyroid stimulating hormone (TSH) level and visual appearance of the residual thyroid gland tissue, and/or with the association of metastatic uptake. The median therapeutic dose of RAI for all patients was $80 \mathrm{mCi}$ in the weeks following surgery. In the presence of residual thyroid gland tissue and metastases (clinical and/or indentified with a 10mCi diagnostic scan), doses of RAI varied from 100 - 200mCi (mean \pm SD 167.5 \pm 43.5 ). The treatment doses for persistent metastatic disease ranged from $100-300 \mathrm{mCi}($ mean \pm SD $183.5 \pm 44.26)$ in a total of 41 therapies, with the majority of patients receiving $>2$ therapeutic doses.

Of the 13 patients who received RAI alone, bone uptake was eliminated with undetectable serum thyroglobulin in 2; 10 had persistent bone uptake but were either asymptomatic or had persistent symptoms; and 1 died 30 months after diagnosis. External beam radiation therapy was used in 11 patients, and in 3 of them as sole treatment. These 3 patients, along with 2 other patients, were treated with external radia-

\begin{tabular}{|c|c|c|c|}
\hline \multicolumn{4}{|c|}{ Table II. Different treatment modalities } \\
\hline Patient no. & Type of surgery & Iodine therapy & Other treatments \\
\hline 1 & TT & + & XRT, thyroxine \\
\hline 2 & TT & + & Thyroxine \\
\hline 3 & $\mathrm{LTL}+\mathrm{RST}$ & + & XRT, thyroxine \\
\hline 4 & TT & + & XRT, thyroxine \\
\hline 5 & TT & + & XRT, thyroxine \\
\hline 6 & TT & + & Thyroxine \\
\hline 7 & RTL & + & XRT, thyroxine \\
\hline 8 & TT & + & Thyroxine \\
\hline 9 & TT & + & Thyroxine \\
\hline 10 & TT & + & XRT, thyroxine \\
\hline 11 & TT & - & XRT, thyroxine \\
\hline 12 & TT & - & XRT, thyroxine \\
\hline 13 & TT & + & Thyroxine \\
\hline 14 & TT & + & Thyroxine \\
\hline 15 & TT & + & Thyroxine \\
\hline 16 & TT & + & Thyroxine \\
\hline 17 & TT & + & Thyroxine \\
\hline 18 & TT & + & Thyroxine \\
\hline 19 & TT & + & Thyroxine \\
\hline 20 & STT & + & XRT, thyroxine \\
\hline 21 & TT & + & Thyroxine \\
\hline $22 *$ & - & - & XRT, thyroxine \\
\hline 23 & RTL+dissec. & + & Thyroxine \\
\hline 24 & STT & + & XRT, thyroxine \\
\hline \multicolumn{4}{|c|}{$\begin{array}{l}\text { *Did not have surgery. } \\
\text { TT = total thyroidectomy; STT = subtotal thyroidectomy; RTL = right total lobectomy; LTL = left total thyroidectomy; RST = right subtotal thyroidectomy; Dissec = dissec- } \\
\text { tion; XRT = external radiation therapy; + = given; - = not given. }\end{array}$} \\
\hline
\end{tabular}


Table III. Metastatic sites, diagnostic modalities and course of disease

$\begin{array}{rr}\text { Patient no. } & \text { Site of bone metastases } \\ 1 & \text { L\&S spine } \\ 2 & \text { Pelvis } \\ 3 & \text { Skull, ribs, pelvis } \\ 4 & \text { Pelvis } \\ 5 & \text { Skull } \\ 6 & \text { Skull } \\ 7 & \text { Skull, pelvis, C spine } \\ 8 & \text { Ribs } \\ 9 & \text { Skull } \\ 10 & \text { Skull, pelvis, sternum } \\ 11 & \text { L spine } \\ 12 & \text { L\&S spine } \\ 13 & \text { Femur } \\ 14 & \text { Sacrum, hip } \\ 15 & \text { Skull } \\ 16 & \text { Skull, ribs, T\&L spine } \\ 17 & \text { Pelvis, femur } \\ 18 & \text { T- spine } \\ 19 & \text { Skull } \\ 20 & \text { Skull, pelvis } \\ 21 & \text { Skull } \\ 22 & \text { Pelvis, T- spine } \\ 23 & \text { Skull, ribs, T\&L spine } \\ 24 & \end{array}$

Diagnostic modalities
X-ray, CT, IS
BS, IS
BS, X-ray, IS
BS, X-ray, IS
MRI, IS
BS, IS
BS,CT, IS
BS, X-ray, IS
BS, X-ray, IS
BS, X-ray, IS
X-ray, CT
BS, X-ray, IS
BS, X-ray, IS
BS, X-ray, IS, CT
BS, X-ray, IS
BS, X-ray, IS
BS, X-ray, IS
CT, IS
BS, X-ray, IS
BS, X-ray, IS, CT
BS, X-ray, IS
BS, X-ray, FNA
X-ray, IS
BS, X-ray, CT, IS

Other metastases/complications

Progression of

disease

$\mathrm{S}$

A

TBMH

TBMH

S

S

US

Lung, brain

A

Increased ICP

Lung

Lung, brain

Paraplegic

Paraplegic

Lung

Lung

Lung

Paraplegic

US

A

A

US

S

$\mathrm{S}$

$\mathrm{AC}$

$\mathrm{S}$

US

A

A

US

AC

US

Proptosis, vision loss

Lung

Unable to walk

Lung

S

US

A

$\mathrm{C}, \mathrm{L}, \mathrm{T}, \mathrm{S}$ spine = cervical, lumbar, thoracic and sacral spine; $\mathrm{Y}=$ done; $\mathrm{N}=$ not done; $\mathrm{BS}=$ bone scan; $\mathrm{CT}=$ computed tomography; FNA = fine needle aspiration; $\mathrm{MRI}=$ magnetic resonance imaging; $\mathrm{TBMH}=$ transient bone marrow hypocellularity; $\mathrm{A}=$ asymptomatic; $\mathrm{S}=$ symptomatic but stable; $\mathrm{US}=\mathrm{unstable} ; \mathrm{ICP}=$ intra cranial pressure; $\mathrm{AC}=$ appear cured; IS = iodine scan.

tion therapy (XRT) at presentation; the remaining 6 patients received XRT later in the course of their disease for symptom control. Of these 11, 4 had clinically improved symptoms, 2 had persistent bony pain, and 5 died. Two patients treated with both of these therapeutic modalities showed transient bone marrow hypocellularity.

In Table III, details of the sites of bone and other metastases, modalities used to demonstrate bony metastases, complications of disease, and patients, progress are shown.

Bone metastases were present on diagnostic (RAI) scans in 17 patients. The other 7 patients developed metastases at a mean of 22 months after diagnosis. The majority of bone metastases were seen in the skull ( 9 patients), followed by spinal regions ( 9 patients), and the pelvis (8 patients). Three patients with spinal lesions were paraplegic, and the pelvic lesions constituted the most extensive bony disease.

Ten patients had other metastases in the lungs, and 2 of them also had brain metastases. One patient with skull lesions experienced recurrence with symptoms of increased intracranial pressure, and another one was admitted via the emergency unit with proptosis and unilateral vision loss.

Seven patients died, 4 from neurological disease directly associated with bone metastases; of the 17 surviving patients, 2 appeared to be disease-free (patients 11 and 12), 8 were asymptomatic despite overt bony diseases for 35 months (range 18 - 148), and 7 had persistent symptoms that were much improved in 5 after 27 months' follow up (range 3 -60).

\section{Discussion}

In our study, bone metastases were uncommon and showed a lower rate of incidence (6.8\%) compared with the estimated published incidence (19-50\%). ${ }^{1,6}$ Seventeen of 24 patients in our group had skeletal metastases at presentation, but these became evident only when clinically visible or when diagnosed by an imaging modality as a result of symptomatology expressed by the patients. This observation explains the phenomenon related to the significant statistical correlation between bone pain and the presence of metastases in oncology patients. ${ }^{7,8}$

We found that those who died were elderly female patients with mainly follicular-type carcinoma. However, several studies have found that gender was not indicative of survival. ${ }^{9-12}$ Those patients who died also had extensive metastatic diseases beyond the skeletal lesions, with the lung being the most common site, followed by the brain. These findings are similar to those of Dimeen et $_{\text {al. }}{ }^{13}$

The predominance of follicular carcinoma in this study correlates with the work of Kalk et al., ${ }^{14}$ who analysed the incidences of papillary and follicular cancers of the thyroid as a function of iodine intake in the South African population.

The female/male ratio in our group echoes the general perception of the disease: our female/male ratio was 3.8:1, which is close to the findings of others. ${ }^{10,15-18}$ All but one patient with papillary cancer were still alive at the time of analysis of these data. All but one of the patients who died had follicular cancer. These findings support views that papillary 
carcinoma has the better prognosis. ${ }^{1}$ Except for 2 patients ( patients 11 and 12 ), all the surviving patients still showed iodine uptake within their bony metastases after more than 2 therapeutic doses of RAI, regardless of current clinical improvement. This fact has been described by other investigators. ${ }^{19-21}$ The data from our study also show the role of XRT together with RAI or as the sole treatment in improving quality of life in patients with bone lesions, which may suggest the need for iodine therapy for all patients showing thyroid uptake on scans following surgery for the primary disease. For large lesions and in patients debilitated by pain, external radiation therapy should be considered to ease and stabilise symptoms.

\section{Conclusion}

Bony metastases were uncommon but, when seen, they tended to manifest at presentation. Follicular cancer predominated in patients in this survey. In most patients with skeletal metastases, RAI improves the quality of life, and treatment with RAI should be recommended in patients with a positive scan following surgery. RAI alone may occasionally eliminate bone metastases, but longer follow-up is needed to verify this approach. There is a definite role for XRT, especially to control bone pain in patients with large bony masses.

1. Samaan NA, Schultz PN, Hickey RC, et al. The results of various modalities of treatment of well differentiated thyroid carcinoma: A retrospective review of 1599 patients. J Clin Endocrinol Metab 1992; 75: 714-720.

2. Muresan MM, Olivier P, Leclre J, et al. Bone metastases from differentiated thyroid carcinoma. Endocr Relat Cancer 2008; 15: 37-49.

3. Durante C, Haddy N, Leboulleux S, et al. Long term outcome of 444 patients with distant metastases from papillary and follicular thyroid carcinoma: benefits and limits of radioiodine therapy. J Clin Endocrinol Metab 2006; 91: 2892-2899.

4. Schlumberger M, Tubiana M, De Vathaire F, et al. Long term results of treatment of 283 patients with lung and bone metastases from differentiated thyroid carcinoma. J Clin Endocrinol Metab 1986; 63: 960-967.
5. Marcocci C, Pacini F, Elisei R, et al. Clinical and biologic behaviour of bone metastases from differentiated thyroid carcinoma. Surgery 1989; 106: 960-966.

6. Tenebaum F, Schlumberga M, Bonnin F, et al: Usefulness of technetium-99m hydroxy methylene diphosphonate scans in localizing bone metastases of differentiated thyroid carcinoma. Eur J Nucl Med 1993; 20 1168-1174.

7. Palmer E, Henrikson K, Mc Kusick K, Strauss HW, Hochberg F. Pain as an indicator of metastases. Acto Radiol 1988; 29: 445-449.

8. Schutte HE, Park WM. The diagnostic value of bone scintigraphy in patients with a low back pain. Skeletal Radiol 1983; 10: 1-4.

9. Wanebo HJ, Andrew W, Kaiser DL. Thyroid cancer: Some basic considerations. Am J Surg 1981; 142: 474479.

10. Mazzaferri EL, Young RL. Papillary thyroid carcinoma: a 10-year follow-up report of the impact of therapy in 576 patient. Am J Med 1981; 70: 511-518.

11. Franssila KO. Is the differentiation between papillary and follicular thyroid carcinoma valid? Cancer 1973; 32: 853-864.

12. Tscholl-Ducommun J, Hedinger CE. Papillary thyroid carcinomas: morphology and prognosis. Virchows Arch 1982; 396: 19-39.

13. Dimeen SF, Valinaki MJ, Bergstralh EJ, Goellner JR, Gorman CA, Hay ID. Distant metastases in papillary thyroid carcinoma : 100 cases observed at one institution during 5 decades. J Clin Endocrinol Metab 1995; 80: 2041-2045.

14. Kalk WJ, Sitas F, Patterson AC. Thyroid cancer in South Africa - an indicator of regional iodine deficiency. S Afr Med J 1997; 87: 731-733.

15. Mc Conahey WM, Hay ID, Woolner LB, Van Heerden JA, Taylor WF. Papillary thyroid cancer treated at the Mayo Clinic, 1946 through 1970: initial manifestations, pathologic findings, therapy, and outcome. Mayo Clinic Proc 1986; 61: 978-996.

16. Meissner WA, Adler A. Papillary carcinoma of the thyroid: a study of the pathology of two hundred and twenty-six cases. Arch Pathol Lab Med 1958; 66: 518-525.

17. Jensen MH, Davis RK, Derrick L. Thyroid cancer: a computer assisted review of 5287 cases. Otolaryngol Head Neck Surg 1990; 102: 51-65.

18. Young RL, Mazzaferri EL, Rahe AJ, Dorfman SG. Pure follicular thyroid carcinoma: Impact of therapy in 214 patients. J Nucl Med 1980; 21: 733-737.

19. Brown AP, Greening WP, McCready VR, Shaw HJ, Harmer CL. Radioiodine treatment of metastatic thyroid carcinoma: the Royal Marsden Hospital experience. Br J Radiol 1984; 57: 323.

20. Maheshwari YK, Hill CS jr, Haynie TP III, Hickey RC, Samaan NA. 131-I therapy in differentiated thyroid carcinoma: MD Anderson Hospital experience. Cancer 1981; 47: 664.

21. Beierwaltes WH, Nishiyama RH, Thompson NW, Copp JE, Kubo A. Survival time and "cure" in papillary and follicular thyroid carcinoma with distant metastases: statistics following University of Michigan therapy. J Nucl Med 1982; 23: 561. 